\title{
Som e movimento em fluxo
}

\author{
Carolina Lage Gualberto \\ Rita de Cassia Santos Buarque de Gusmão \\ Departamento de Artes Cênicas, Escola de Belas Artes, \\ Universidade Federal de Minas Gerais, Brasil \\ Jussara Rodrigues Fernandino \\ Departamento de Teoria Geral da Música, \\ Universidade Federal de Minas Gerais, Brasil
}

DOI: https://doi.org/10.31492/2184-2043.RILP2020.37/pp.33-46

\begin{abstract}
Resumo
Este artigo apresenta uma investigação em andamento, desenvolvida pelo Núcleo Voz e Movimento do Laboratório de Experimentação e Criação em Artes Cênicas - LECA - que tem como base a interação entre os princípios das pedagogias da Dança, da Música e do Teatro, voltados para o processo criativo de cenas. Tal pesquisa visa à elaboração de procedimentos de treinamento e de composição em processos cênicos que realizem a interação entre música, movimento e atuação. Apresenta-se a ideia de que a potencialização expressiva se constrói no treinamento e se opera na manifestação artística, pelo entrelaçamento dos fluxos espacial, temporal e de esforço. Fundamentam a pesquisa princípios de Rudolf Laban (1978), a noção de fluxo de Mihaly Csikszentmihalyi (2008) e a de iteração de Jacques Derrida (1986). Até o momento, a pesquisa tem demonstrado que as práticas experimentadas têm sido coerentes e resultado de forma consistente na elaboração de cenas, nas quais os participantes se percebem aptos em si mesmos para elaborar e manter ações coordenadas seja com outros participantes, com objetos e com o espaço.
\end{abstract}

Palavras-chave: fluxo; interação cênico-musical.

\begin{abstract}
This article presents an ongoing investigation, developed by the Voice and Movement Nucleus of the Laboratory of Experimentation and Creation in Performing Arts - LECA - which is based on the interaction between the principles of the pedagogies of Dance, Music and Theater, focused on the creative process of scenes. This research aims to elaborate training and composition procedures in scenic processes that perform the interaction between music, movement and performance. It presents the idea that expressive potentiation is built in training and operates in artistic manifestation, by the intertwining of spatial, temporal and effort flows. The research principles of Rudolf Laban (1978), the notion of flow of Mihaly Csikszentmihalyi (2008) and the iteration of Jacques Derrida (1986) are based on the research. To date, the research has shown that the practices experienced have been coherent and consistently result in the elaboration of scenes, in which the participants perceive themselves able to elaborate and maintain coordinated actions either with other participants, with objects and with space.
\end{abstract}

Keywords: flow; scenic-musical interaction.

A investigação aqui apresentada reúne uma atriz, uma dançarina e uma musicista, e visa à elaboração de procedimentos de treinamento e de composição de processos criativos que realizem a interação entre música, movimento e atuação na cena. Este desafio foi assumido pelo Núcleo Voz e Movimento do Laboratório 
de Experimentação e Criação em Artes Cênicas - LECA ${ }^{1}$ - e tem como ponto de partida princípios das pedagogias da Dança, da Música e do Teatro. As participantes atuam na Escola de Belas Artes e na Escola de Música da Universidade Federal de Minas Gerais (UFMG), Brasil.

O objetivo geral é o de conhecer com maior aprofundamento as possibilidades expressivas de cada uma das faces dessa tríade artística, considerando-as como uma rede a partir da qual artistas podem aprimorar sua atuação.

Como objetivos específicos, está se buscando desenvolver o trânsito entre estas artes no sentido de que a consciência de ações sonoras e de movimento pode promover a dilatação da percepção cinestésica própria do artista, levando a uma comunicação melhor desenhada com o público; está se buscando desenvolver práticas que promovam a retroalimentação entre elas, no sentido de que a harmonização de esforços corporais para a realização das ações em cena pode imprimir maior potência a estas, levando a uma relação energética com a plateia que extrapole a energia cotidiana de diálogo, situação esta de que a cena necessita.

Em termos de pedagogia acreditamos num conceito que diz que "ação e reflexão [são] de tal forma solidárias, em uma interação tão radical que, sacrificada, ainda que em parte, uma delas, se ressente imediatamente a outra" (Freire, 2002, p. 77). Acreditamos que os princípios da Pedagogia da Autonomia, de Paulo Freire, proporcionam a mais adequada base para o procedimento de elaboração do treinamento para a prática artística que se almeja com esta pesquisa. Estes princípios foram resumidos por Freire nas seguintes recomendações: ensinar requer rigorosidade metódica; ensinar exige pesquisa; ensinar exige respeito aos saberes dos educandos; ensinar exige criticidade; ensinar exige estética e ética; ensinar exige a corporeificação das palavras pelo exemplo; ensinar exige risco, aceitação do novo e rejeição a qualquer forma de discriminação; ensinar exige reflexão crítica sobre a prática; ensinar exige o reconhecimento e a assunção da identidade cultural (Freire, 2003).

Do ponto de vista da pedagogia do Teatro, trabalhamos com a perspectiva de teatro contemporâneo, o que quer dizer um campo formado por uma abordagem da cena ligada à representação, mais que à interpretação, e que, por isto, produz formas específicas de criação, de formalização e de recepção. Nesta perspectiva, o produto é ainda processo, os criadores e criadoras estão em situação de horizontalidade e a poética da cena advém de variadas fontes iniciais, não se prendendo ao texto dramatúrgico apenas. Nesta perspectiva, também, se desconstrói "sistemas clássicos de narrativa (construção aristotélica, uso de trama,

1. Grupo de pesquisa inscrito no CNPq (Conselho Nacional de Desenvolvimento Científico e Tecnológico), liderado por Rita Gusmão. 
dramaturgia, personagens, desenlace, causalidades)", em busca de "estruturas de organização": sincronicidades, risco, captação de elementos do campo pessoal do artista, teatralidade ao invés de verossimilhança, composição a partir do espaço, dos sons ou de imagens externas ao artista (Cohen, 1998). Há também aqui uma relação com as tecnologias e o trabalho em rede telemática como suportes de expressão e encenação. Esta pedagogia se desenvolve por meio de pesquisa continuada, atividades corporais que promovam autoconsciências física e emocional, exercícios criativos para a conquista de autonomia estética de cada participante e composição com outras Artes.

Em consonância com a perspectiva de pedagogia do Teatro com a qual trabalhamos, a pedagogia em Dança à qual se vincula este estudo, tem como fundamento o autoconhecimento corporal do sujeito numa perspectiva de totalidade, distante da dicotomia cartesiana corpo versus mente. Nesse sentido, o processo pedagógico em Dança que buscamos nos aproximar é desfragmentado e acontece a partir do reconhecimento corporal que o sujeito tem de si mesmo no cotidiano e que o permite perceber camadas profundas de seu si mesmo, que atuam durante o treinamento como construtoras de um processo de aprendizagem contínuo. Desse modo, esta pesquisa toma como premissa que o movimento em dança é construído muito antes de um treinamento corporal e segue se constituindo e se modificando fora do tempo de treinamento, uma vez que o corpo do sujeito está numa constante dinâmica de trocas com seu entorno. Esta prática atenta é necessária na contemporaneidade, uma vez que estamos "acostumados a introjetar a ordem à nossa volta [e] habituamo-nos a não olhar, não ouvir, não sentir intensamente e desprezar a importância dos fatos e acontecimentos menores, quase imperceptíveis - embora fundamentais" (Vianna, 2005, p. 73). O objetivo desta pedagogia é o autoconhecimento, tanto como parte do processo pedagógico em Dança, que gera no sujeito atenção, quanto na busca do desenvolvimento da habilidade de percepção ampla de vivências, de movimentos que se enlaçam na construção de si mesmo e da subjetividade.

A investigação contínua de si mesmo e a prática atenta às particularidades de cada sujeito fazem parte do trabalho de Rudolf Laban (1978), que em suas propostas de estudo do movimento considera movimentos cênicos e cotidianos numa perspectiva de ação corporal, que por sua vez, é composta por uma correlação emocional, física e intelectual. Acerca da ação corporal, podemos ressaltar que:

Ação e/ou ação corporal é uma sequência de movimentos onde uma atitude do agente resulta num esforço definido, o qual, por sua vez, imprime uma qualidade ao movimento. ...Laban ressalta que atitude, esforço e movimento dão-se simultaneamente e que o termo corporal engloba os aspectos intelectuais, espirituais, emocionais e físicos, ou seja, o corpo é uma totalidade complexa. Há infinitas 
ações: correr, torcer, pular, engatinhar, saltitar, enfim todas as ações que os agentes fazem, sempre com a ideia de Laban de que a ação não é só física ou mecânica (Rengel, 2015, p.32).

Com o objetivo de aprofundar a análise e a compreensão das relações expressivas entre som e movimento, nos aproximamos do estudo de Laban, de onde parte o princípio geral para as práticas corporais que vimos desenvolvendo no momento atual da pesquisa. Com o objetivo de proporcionar ao praticante um treinamento artístico, que consistisse em exercícios destinados a treinar o corpo como um instrumento de expressão, adotamos o princípio de Laban de se tornar consciente das várias articulações do corpo e de seu uso na criação de fluxos rítmicos e espaciais. Convergimos também com a necessidade de "apercerber-se do estado de espírito e da atitude interna produzidas pela ação corporal" (Laban, 1978, p.38). Esta ação corporal é apresentada por Laban como resultado de um impulso interno que acontece durante um tempo determinado, em determinado espaço e com certo esforço empregado.

Em relação à Pedagogia da Autonomia de Freire e suas ideias de valorização dos diversos saberes e identidades culturais que constroem os corpos dos sujeitos, pensamos que convergem com esta perspectiva adotada pela pesquisa, no sentido de buscar a pedagogia relacionada à potencialização expressiva e artística, na qual se consideram diferentes pontos de partida e de chegada, com metodologias que se constroem durante os processos, uma vez que o trabalho deve acontecer relacionado às distintas corporeidades que se apresentam. Nesse sentido, a pedagogia em Dança que aqui se apresenta, se desdobra em vários procedimentos pedagógicos que têm fundamentos comuns, e possuem, cada um, elementos próprios e direcionados à proposta artística a ser realizada.

Com relação à pedagogia da Música, esta tem como ponto gerador o desenvolvimento da musicalidade do indivíduo, anterior, ou ao menos paralela, à aquisição de técnicas teórico-instrumentais. Considera-se, assim, o desenvolvimento de potencialidades que, gradativamente, alcancem a experiência musical e a apreensão de sua linguagem. Isso se dá em processos contínuos de musicalização em seus meios de percepção, expressão e pensamento (Penna, 2010); incluindo-se aí os aspectos expressivos e culturais pertinentes ao próprio universo musical do sujeito. Dentro de um espectro pedagógico amplo, existem diferentes caminhos e abordagens didático-musicais que foram sendo constituídos historicamente e que não raro se complementam.

A pesquisa aqui apresentada lança mão, especificamente, de princípios de algumas dessas contribuições. Émile Jaques-Dalcroze (1980) é um nome referencial por sua proposta de relação entre música e movimento corporal, perpassando a 
conexão entre as dimensões físicas, afetivas e cognitivas. Na metodologia dalcroziana, a primeira forma de compreensão deve vir por meio da experiência sensorial e motora. Esta experiência é promovida pela estimulação sonora, com vistas ao desenvolvimento da consciência rítmica, da escuta ativa e da expressividade, e envolve três sistemas básicos: a música (ritmo, melodia, harmonia), o movimento (sensação gestual, plasticidade, expressividade) e entre eles, articulando-os, o corpo (eixo, equilíbrio, lateralidade, respiração, sistema neurossensorial).

Outra referência de interesse para a pesquisa são os princípios da pedagogia Carl Orff (1973), no que tange as possibilidades interativas dentro da configuração música-movimento-fala. Nessa concepção, a linguagem, a música e o movimento são interligados pelo fenômeno rítmico e, dessa forma, o corpo é utilizado em suas possibilidades gestuais e de produção sonora, tais como a locomoção rítmica, a percussão corporal, bem como a exploração do potencial da linguagem falada por meio do jogo sonoro e rítmico das palavras. É interessante notar que Laban, em suas pesquisas em torno da Dança-Teatro, também desenvolveu o sistema Tanz-Ton-Wort (dança, som, palavra), buscando o entrelaçamento e o diálogo entre esses aspectos (Lima, 2008).

E ainda dentro do campo musical, e tendo como base os pedagogos da linha contemporânea, destacam-se os processos desenvolvidos por John Paynter (1972) e Murray Schafer (2012). Suas propostas apresentam dois aspectos fundamentais que são a ampliação do conceito de escuta e a criação como centro da ação pedagógica. Outros pontos em comum são a proposição didática por meio de projetos, em lugar de um método linear; a valorização da descoberta; e o emprego do som como matéria prima, envolvendo, na pesquisa das sonoridades, a utilização de fontes sonoras diversas - convencionais e não convencionais - e a sensibilização ao silêncio.

O conceito que nos parece gerar uma tal relação entre as Artes do som, do movimento e da cena é o de fluxo. O psicólogo Mihaly Csikszentmihalyi elaborou um conceito para fluxo que reúne elementos fundamentais para esta pesquisa, a saber: o fluxo é uma experiência, se caracteriza como um momento de imersão total numa atividade compatível com as habilidades do sujeito, esta experiência leva a uma sensação de bem-estar, esta experiência é intensa a ponto de alterar a percepção de tempo (Araújo, 2008, p.39-52). Buscamos relaciona-lo com as atitudes individuais a serem adotadas e fortalecidas durante o treinamento e que nomeamos como princípios. Estes princípios serão também elementos do processo criativo das cenas: Intencionalidade, Iteração, Delineamento rítmico e Dinamização da energia expressiva. São apresentados aqui cada qual em sua descrição, numa ordem que nos parece demonstrar que são uma rede e não uma sequência, e que funcionam, na prática, de maneira interligada. 
$\mathrm{Na}$ perspectiva desta investigação, o fluxo contém a camada individual de experiência envolvente e criadora, convergindo com a proposta de Mihaly, e se amplia para a ação de um corpo sobre um outro corpo, na qual o corpo sobre o qual se age pode ser humano ou objetual, como um instrumento musical, um mobiliário ou uma vestimenta. O fluxo ao qual se dedica o artista faz revelar também a ação do incorpóreo sobre o incorpóreo, o que pode ser entendido como o envolvimento da consciência, da percepção e da habilidade de atenção com o aspecto ficcional que a manifestação artística proponha aos seus participantes, artistas e não artistas. O fluxo se estabelecerá desde a experiência propriamente dita até o olhar reflexivo sobre ela, que faz o artista apreender uma essência própria ao seu si mesmo, a ser captada, conscientizada e ampliada com as fases do treina-mento, e que será um conteúdo que pode ser considerado sua característica intrínseca e individuali-zada, fundamento para o processo criativo.

$\mathrm{Na}$ elaboração da manifestação artística, o fluxo alimenta um jogo de fricções entre códigos que vão sendo escolhidos no decorrer do processo criativo, e este jogo se realiza na fricção entre simbólico e semiótico, entre caos e ordem, a partir da qual o artista atua. Dessas fricções surgem as alternâncias entre composição e recomposição da manifestação, a cada realização dela, seja no contexto de ensaios seja no de apresentações. Estas fricções potencializam o fluxo e o conectam com a materialização dele em processos expressivos que constituem a manifestação artística.

A perspectiva de potencialização expressiva se baseia numa noção de potência criadora que se expressa como uma rede de estímulos, a ser alimentada por e direcionada para variadas linguagens artísticas. Podemos compreendê-la como a conscientização da série de esforços simultâneos (mentais, afetivos e físico-motores) que se equilibrarão delicadamente entre si, na medida em que sejam genuínos impulsos internos, originadores de movimentos e de gestos musculares e rítmicos. Esta pesquisa está em busca de um processo de desenvolvimento da atitude criadora que faça interagir corpo e percepção crítica deste, de modo que o artista alcance uma inteireza de suas ações e, conseguintemente, de relação equilibrada e consciente entre técnicas aprendidas, movimento criador e relação com o fruidor. As atividades de treinamento têm como objetivo potencializar, isto é, tornar vigorosas e visíveis, as características individuais em função de fortalecer o processo criativo.

Esta potencialização expressiva se constrói no treinamento e se opera na manifestação artística, pelo entrelaçamento dos fluxos espacial, temporal e de esforço; estes fluxos são pensados aqui como constituintes uns dos outros e tendo como canais de efetivação a produção sonora e o movimento, amalgamados nas 
elaborações expressivas. Acreditamos e partimos do pressuposto de que o equilíbrio dos esforços simultâneos é capaz de gerar prazer estético para o próprio artista, além de converter o corpo em instrumento sensível capaz de elaborar e realizar a manifestação da inter-relação entre mundo interior do artista e mundo exterior, onde se dá a manifestação artística.

Compreender a rede que se estabelece na relação entre os fluxos temporal, espacial e de esforço é fundamental para poder pensar som, movimento e elaboração expressiva de forma entrelaçada, num treinamento que, de fato, seja significativo para o aprimoramento artístico.

O fluxo espacial no contexto da cena se apresenta em duas camadas de percepção: o corpo no espaço, isto é, o espaço como referência direcional do corpo; e o espaço no corpo, ou seja, espaços definidos a partir do corpo e como parte dele. Estas duas camadas são a base do estudo da organização espacial realizado por Laban - chamado por ele de Corêutica ${ }^{2}$. Neste estudo, o autor afirma que o espaço se relaciona com o onde acontece o movimento, enquadrando-se nele o alcance do movimento, o percurso espacial, a tensão espacial, as formas geométricas em relação ao espaço e às escalas de espaço, como condutores vetoriais do fluxo.

A relação entre os espaços interno e externo ao corpo é fundamental para a compreensão de como o eu se relaciona com o que o cerca, do fato de que estamos em perene constituição entre micro e macro e, nesse sentido, compreender o corpo para compreender o mundo. É a partir desta perspectiva que Klauss Vianna aponta que:

\footnotetext{
...existe um espaço interior, emocional, mental, psicológico, e um espaço exterior que é onde se manifesta a dinâmica do corpo. A sensação de equilíbrio corresponde ao momento ou aos momentos em que descobrimos uma maneira harmônica de utilização do espaço, em que equilíbrio interior e exterior já não se diferenciam mais. O homem se insere nesse universo e atua como síntese desse universo. (Vianna, 2005, p.121)
}

Assim, entende-se que existe uma dinâmica contínua entre o espaço e o corpo-sujeito e que ambos estão constantemente em construção. Nesse sentido, todo e qualquer movimento, por menor que seja, transforma o espaço. Uma vez vivo e em transformação, o espaço não é nunca um vazio assemelhado ao nada, mas um vazio que é o incorporal e o invisível. Na perspectiva da relação entre espaço e movimento, salienta-se aqui a ideia de que não se pode separar movimento e

2. A Corêutica também é conhecida como "arquitetura do movimento". Nesse sentido, usando o corpo e o seu espaço externo, a Corêutica tem como elemento principal de exploração do movimento a Cinesfera. Por meio do estudo dos planos e das dimensões espaciais da Cinesfera, acontece o estudo das formas do corpo no espaço. Laban resumiu essas formas em cinco formas geométricas: tetraedro, octaedro, cubo, icosaedro e dodecaedro. 
espaço uma vez que "o movimento é um contínuo fluxo dentro da localidade e ele mesmo é um aspecto fundamental do espaço" (Laban apud Rengel, 2015, p.40).

Compreender o espaço vivenciado no corpo e por ele, gera efeitos positivos na percepção do ritmo e na relação com a voz. Uma vez que tempo e espaço são um amálgama e que constituem o movimento, o trabalho realizado em um determinado espaço, bem como a consciência deste percurso espacial permite ao corpo a compreensão do tempo necessário para a realização de determinado movimento. Na relação com a voz, esta percepção espacial possibilita uma conexão aguçada e afinada com a intencionalidade do artista, na medida em que permite compreender o espaço que a voz ocupa e, assim, utilizá-la alinhada com a ação intencionada, potencializando sua expressão.

Como o vetor espaço incide sobre e promove a compreensão de si e a noção de lugar para os outros componentes da cena, seu sentido e sua própria vetorização como elemento expressivo realizam-se nas relações de comunicação, de troca entre o interno e o externo ao artista. As atitudes que promovem este fluxo espacial são a atenção e a afecção em relação ao foco do movimento. Para a cena, a elaboração da conexão consigo e com os outros significa a organização de um estado preciso de atenção, sendo esta última constituinte fundamental da energia expressiva. É importante ressaltar que se deve partir do entendimento de que espaço, tempo e esforço se realizam um no outro, na medida em que são indissociáveis na construção do movimento e na relação de elaboração da cena.

Por sua vez, o fluxo temporal contém aspectos da musicalidade, sendo estes não apenas os fatores relativos à Música, propriamente dita, mas também concernentes à gestualidade, ao movimento e à palavra. Nesse contexto de interação, o ritmo aparece como um fator preponderante, pois envolve a articulação e a organização expressiva do fluxo temporal de caráter estruturante e suas relações com os fluxos de esforço e de espaço. Entende-se, aqui, por organização, não apenas o que direciona informações de forma lógico-linear, mas também os aspectos que contemplam a irregularidade rítmica - deslocamentos, rupturas e quebras da unidade de ação.

O ritmo pode ser entendido como manipulação do tempo (Penna, 2010) e, de acordo com o tratamento dos elementos expressivos empregados, pode manifestar-se em formas métricas e não-métricas. O compasso musical, por exemplo, é uma proposição de caráter métrico e é capaz de ordenar e conduzir ritmicamente uma atuação. As possibilidades não-métricas são as que prescindem de recursos de medida e contagem, mas que empregam outros meios de estruturação, tais como arcos respiratórios, ciclos de ação, coordenação entre tensão e repouso. Nessas relações, para além de uma ritmicidade proveniente de uma estimulação 
externa, o atuante "torna-se ritmo... por meio de harmonização de impulsos do corpo, retenções e apoios, no tempo e no espaço" (Moura, 2007, p.66).

$\mathrm{O}$ estudo da sonoridade contribui para o entendimento de princípios básicos do ritmo em suas diversas possibilidades, e o contato com fontes sonoras diversas tomadas como material expressivo - a voz, o corpo, os objetos, os instrumentos musicais, os meios eletrônicos - se desenvolvidas em conexão com os aspectos cênicos e cinestésicos, possibilitam a compreensão do desenvolvimento da temporalidade.

Do ponto de vista dessa investigação, este estudo passa pelo desenvolvimento da percepção de si em iteração com a materialidade corpórea, espacial e de esforço. A voz, por exemplo, em suas possibilidades de som e de palavra, pode se conectar a aspectos corporais relacionados ao gesto, ao movimento, à espacialidade, gerando imagens sonoras, visuais e cinestésicas. Para tal, devem ser estimuladas a coordenação e a retroalimentação dessas diferentes informações, por meio de práticas que promovam "a relação executante-informação, a regulação espaço-temporal, a elaboração de referências cinético-sonoras" (Fernandino, 2014).

Dizemos iteração pensando que o treinamento do artista para desenvolver a habilidade de imergir em fluxo, se aproxima da noção de iteração proposta por Jacques Derrida: processo de percepção que se repete em ciclos e chega a resultados não pré-definidos, e que a cada vez gera um resultado parcial que será usado na continuidade do próprio jogo perceptivo (DERRIDA, 1986). Esta noção de iteração, em todos os seus eixos, contribui sobremaneira para a atitude criadora consciente: o exprimível no desenvolvimento da capacidade de simbolizar; o tempo no aprendizado do tornar-se; o vazio como elemento estético; a percepção da transformação e do movimento como elementos estéticos; o lugar, na percepção da cena como espaço de intervenção sociocultural ampliada e sensível. A iteração se dá como a busca continuada de sensações intensas e motivacionais para que o artista se mantenha ativo e consciente no momento presente da sua atividade criadora (Gusmão, 2014).

A iteração compõe uma dinâmica de relações orgânicas entre os fluxos internos e externos ao artista, possibilitando que seu corpo, treinado e autônomo, possa organizar transições para si mesmo e para a interação com o fruidor, parceiro último da cena. Nesta interação com iteração, se torna mais consciente a perspectiva de estabelecer e manter uma linha de temporalidade, de atribuir sentidos aos acontecimentos e o fazer em conjunto, mesmo que num acordo silencioso e intuitivo. Neste movimento uma espécie de pensamento sonoro, de pensamento em sons e silêncios em ritmo, favorece a troca e mantém o vínculo afetivo com os fruidores, fazendo equivaler as intenções, atenções e reações numa dinâmica que 
nesta pesquisa chamamos de Dinamização da Energia Expressiva: a compreensão das redes espaciais, temporais e de esforços para realizar o fluxo expressivo.

Cabe ainda ressaltar que a consciência da ação expressiva demanda um estado de escuta. Pierre Schaeffer (1966), distingue quatro modos de escuta que, definidas de maneira sintética, consistem em: Escutar - atitude ativa e interesse pela identificação da informação sonora; Ouvir - recepção física e passiva do som; Entender - seleção e intenção de escuta, relativas a experiências e preferências do ouvinte; e Compreender - percepção que, por meio de abstração, comparação e dedução, busca atribuir significado à informação imediata. Nessa linha, outros nomes tais como John Cage (1985) e Murray Schafer (Op. Cit.) apontam a troca de informações entre ouvinte e ambiente em nível de construção de significados, defendendo uma escuta que não somente organiza o ambiente acústico a sua volta, mas que também o compõe, que o inventa (Santos, 2004). Dessa forma, mais que um receptor o ouvinte pode tronar-se, simultaneamente, um atuante e um criador.

Essa perspectiva ampliada de escuta se aproxima do sentido de presença, como empregado na atuação cênica. Esta implica um estado de conexão e uma energia diferenciada do cotidiano, num corpo com teatralidades. Acreditamos que no instante da escuta, assim como na presença de fato, acontece um liame temporal entre o sujeito e o objeto de sua atenção, um fluxo, que, por sua vez gera um tônus conscientizado no sujeito que se coloca em iteração e em interação, e que Eugênio Tadeu Pereira denomina tônus atitudinal (Pereira, 2015).

O esforço é compreendido nessa pesquisa, como tônus atitudinal do agente quando busca amalgamar suas ações num sistema corporal consciente e intencionado. O esforço se estabelece em fluxo, e resultará em manifestação artística na medida em que este agente estabeleça um plano de ações espaciais, temporais e expressivas com um objetivo sensibilizador e interativo pré-definido. A potencialização se dará na medida em que esta série de esforços traduzir genuínos impulsos internos que, por sua vez, se originam e motivam a rede de movimentos, sons e gestos. Esta série de esforços se realiza a partir da percepção e da manutenção de um delineamento rítmico, cuja função é a integração harmoniosa dos próprios esforços. Esta harmonia, que chamamos aqui de Delineamento Rítmico, pode ser entendida como o conhecimento da coordenação de esforços e das harmonias da trajetória do movimento e do som no espaço, na experiência de seu entrelaçamento com tônus atitudinal.

Entendemos que o delineamento rítmico é essa composição possível a partir da conscientização e compreensão de seus elementos constitutivos sonoros 
e cinestésicos, e pela determinação de seus ciclos de ação, isto é, início, desenvolvimento e finalização de cada ação expressiva. Dentro desses ciclos se dá a identificação e o uso consciente dos ritmos, microrritmos, tensões e repousos, que definem ações e microações, bem como, as possibilidades de retenção (pausa dinâmica) e desencadeamento (descarga dinâmica) em cada uma delas. Este objetivo é uma composição múltipla, que resultará em uma criação artística na medida em que se vincular a uma intencionalidade explícita.

Quando pensamos em intencionalidade estamos falando da compreensão dos matizes delicados do estado de espírito presentes na composição expressiva, simultaneamente a relaciona-los com o enfoque mental adequado para a elaboração do movimento e do som que o traduzirão para a comunicação com o ambiente e o outro. É como a forma plasmável do esforço: que apreende de onde vem seu centro, quais elementos serão desenvolvidos e em qual ritmo e mantendo o estado de consciência estável e não controlador. A intencionalidade é uma espécie de adesão somática à ação que desencadeia diálogo verdadeiro entre corpo e mente no momento presente de cada ação, ativando o jogo e evita sua encenação, a presença mais que a realização do roteiro prévio de movimentos e sons, a troca.

Esse treinamento requer, num primeiro momento, o contato e a compreensão dos elementos expressivos no corpo, sendo estes a voz, o tônus, os objetos, o espaço e os artifícios de medida do tempo. Todos estes elementos tomados como material expressivo e em conexão, serão fonte de elaboração de imagens (sonoras, visuais, cinestésicas) e contribuirão para o entendimento do ritmo e de sua potência de ação. Devem ser estimuladas práticas que promovam o desenvolvimento de um repertório sensório-motor, de acesso ao fluxo de elementos sonoros, cinéticos, visuais e espaciais, da memória e, simultaneamente, de habilidade de coordenação de aspectos escolhidos deste repertório. Pensa-se que este acesso é a própria conquista de uma regulação espaço-temporal consciente do artista, que o habilita à elaboração de referências cinéticas e sonoras orgânicas entre si e consistentes.

Um segundo momento, será o de compreensão de processos expressivos individuais em relação aos estímulos externos, que pode ser entendido como uma escuta de caráter interacional que passa pela captação e pelo gerenciamento criativo dos diversos elementos expressivos que ocorrem simultaneamente no momento da elaboração e da realização da manifestação artística, sejam sonoros, corpóreos, visuais, espaciais e de diálogo.

Cabe ressaltar que os processos serão desenvolvidos na medida da apropriação individual dos participantes de conhecimentos acerca dos fluxos, da conscientização e amadurecimento da habilidade de acessá-los no decorrer do 
treinamento e do processo criativo. Este treinamento não se desenvolve apenas numa dimensão físico-mecânica, mas em uma prática consciente e contínua, nos níveis conceitual, técnico e perceptivo-expressivo. Esta investigação busca desenvolver estratégias de apreensão destas possibilidades expressivas, promovidas por meio de processos de sensibilização e de criação.

Esta é uma pesquisa em andamento e tem como núcleo de trabalho um grupo de estudos formado pelas pesquisadoras, no qual ocorre a leitura e a reflexão em torno de obras das áreas envolvidas, bem como experimentações e desenvolvimento de práticas de interação. Uma vez que o viés pedagógico perpassa os fundamentos da investigação, o conhecimento desenvolvido tem sido aplicado em projetos e disciplinas das escolas de Belas Artes e de Música da Universidade Federal de Minas Gerais, abrangendo alunos dos cursos de graduação em Dança, em Música e em Teatro, e estabelecendo, assim, a relação entre pesquisa e ensino. Dentre as ações desenvolvidas pelo grupo, até o momento, consta a adaptação para a cena teatral do texto Macunaíma, de Mário de Andrade no ano de 2017; o desenvolvimento de trabalhos junto ao grupo de contação de histórias Cantarines, em 2017 e 2018; a aplicação dos estudos nas disciplinas intituladas Práticas cênico-musicais e Música e Expressão Corporal, em 2017 e 2018; a realização do Seminário Voz e Movimento, promovido pelo Laboratório de Experimentação de Criação em Artes Cênicas, em 2018; e a participação no II Colóquio Internacional: Escrita, Som, Imagem, realizado pela Faculdade de Letras da UFMG em 2019.

Não se pode dizer que esteja plenamente definido o treinamento, que vem sendo gradativamente sistematizado. Contudo, as práticas que temos experimentado têm sido coerentes e resultado de forma consistente no contexto da pedagogia das artes da cena e da música, nas quais os participantes se percebem aptos em si mesmos para elaborar e manter ações cênicas escolhidas. Verificamos que a potencialização expressiva vem sendo alcançada e, considerando a especificidade dos diferentes cursos de graduação atendidos, as possibilidades de troca e interação entre as linguagens artísticas têm se demonstrado também uma forma de ampliação da formação dos participantes.

Uma experiência que pode ser relatada aqui, a título de ilustração, é da elaboração de uma contação de um conto das Mil e uma Uma Noites, foco de uma experimentação cênica voltada para o aprimoramento da voz em sua relação com o movimento na cena, em 2017, na qual foi verificado um estado de retroalimentação entre essas possibilidades. Numa das cenas, a fala doce e magoada de um pai que estava ameaçado por uma maldição de perder seu único e tardio filho, não deslanchava por causa de uma inabilidade de atores e atrizes de a colocarem em 
um ritmo intenso, porém, doce como a sua leitura a todos inspirava. Um exercício lhes trouxe a possibilidade de percepção espacial da voz e lhes proporcionou a habilidade de utilizar a voz como uma atitude emocional: mover o braço e o antebraço conjuntamente na direção do alto, girando em um pequeno semicírculo de dentro para fora do corpo, enquanto entoavam a fala do personagem pai. No momento em que braço e voz se uniram para ocupar o espaço em redor de cada corpo, a voz seguiu o arco lento e pequeno que o braço desenhou e a intencionalidade como que brotou dos músculos com decisão. A voz se afinou e um canto dolorido e delicado se fez no ar... A cena tomou proporções de tragédia e se completou com a repetição do movimento do outro braço no ar, seguido pelo arco dos dois braços simultaneamente. A simplicidade da ação encorajou os participantes, inclusive, a novas experiências cinestésicas para entoar a voz e a palavra no decorrer da contação do conto.

Experiências desta natureza têm sido realizadas em sala de aula e em oficinas, compondo o roteiro de treinamento que almejamos sistematizar. Cada exercício tem variantes e permitem a solução de dificuldades corporais, além de ter tomado o lugar de um treinamento técnico clássico, no qual a repetição exaustiva de uma fórmula evita a apropriação poética pelo participante de elementos técnicos que o auxiliem a desenvolver seu próprio modo de operação e composição, adequado a seus objetivos e desejos artísticos.

Esperamos trocar propostas com pesquisadores e pesquisadoras sobre estes temas a partir deste artigo.

\section{Referências}

Araújo, R. C. (2008). Experiência de fluxo na prática e aprendizagem musical. Revista UFPR, v. 1, n. 2.

Cohen, R. (1998). Work in progress na cena contemporânea: Criação, encenação e recepção. São Paulo: Ed. Perspectiva. (Coleção Estudos).

Cage, J. (1985). De segunda a um ano: novas conferências e escritos. São Paulo: Hucitec.

Csikszentmihalyi, M. (2008). Flow: The psychology of optimal experience. New York: HarperCollins.

Derrida, J. (1986). Margens da Filosofia. Tradução: Joaquim Torres Costa e António M. Magalhães. Porto/Portugal: RÉS-Editora.

Fernandino, J. R. (2014). A interação cênico-musical nos processos de formação de músicos e atores. Anais do XXIV Congresso da Associação Nacional de Pesquisa e Pós-Graduação em Música (ANPPOM). São Paulo.

Freire, P. (2002). Pedagogia do Oprimido. 32a . Edição. Paz e Terra: Rio de Janeiro. 
(2003). Pedagogia da Autonomia: saberes necessários à prática educativa. São Paulo: Paz e Terra.

Gusmão, R. C. S. B. (2014). De espectador a fruidor coautor: diferentes relações na cena ao vivo contemporânea. Tese (doutorado). Instituto de Artes, Universidade de Brasília, Brasília.

Jacques-Dalcroze, É. (1980). Rhythm, Music \& Education. London: Dalcroze Society.

Laban, R. (1978). O domínio do movimento. São Paulo: Summus.

Lima, C. A. S (2008). Dança-Teatro: a falta que baila. Escola de Belas Artes, Universidade Federal de Minas Gerais, Belo Horizonte.

Moura, E. (2007). Manipulações do Tempo em Música - uma Introdução. Revista Claves, n.4.

Orff, C. (1973). Orff Schulwerk: past and future. Cleveland Heights, Ohio: Orff-Schulwerk American Association.

Paynter, J. (1972). Hear and Now: an introduction to modern music in schools. London: Universal Edition.

Penna, M. (2010). Música(s) e seu Ensino. Porto Alegre: Sulina.

Pereira, E. T. (2015). Práticas lúdicas na formação vocal em teatro. São Paulo: Hucitec.

Rengel, L. (2015). Dicionário Laban. $1^{\text {a }}$ edição digital. Curitiba: Ponto Vital.

Santos, F. C. (2004). Por uma escuta nômade: a música dos sons da rua. 2. ed. São Paulo: EDCUC/ FAPESP.

Schaeffer, Pierre (1966). Traité des objects musicaux: essai interdisciplines. Paris: Éditions du Seuil.

Schafer, M. (2012). O Ouvido Pensante. São Paulo: Editora UNESP.

Vianna, K. (2005). A Dança. São Paulo: Summus Editorial.

Data receção: 25/09/2019

Data aprovação: 30/04/2020 